\title{
An Intelligent Semi-Latin Square Construct for Measuring Human Capital Intelligence in Recruitment
}

\author{
Emmanuel C.Ukekwe ${ }^{1}$, Francis S. Bakpo ${ }^{2}$, Mathew C.Okoronkwo ${ }^{3}$, Gregory E.Anichebe ${ }^{4}$ \\ Department of Computer Science \\ University of Nigeria, Nsukka, Enugu, Nigeria
}

\begin{abstract}
Processing speed and memory recall ability are two major Human Capital Intelligence attributes required for recruitment. Matzel identified five domains of Intelligence. Unfortunately, there were no stated means for measuring them. This paper presents a framework for measuring Processing speed and Memory intelligence domains using Sternberg and Posner paradigms of short memory scanning test. A Semi-Latin square was constructed and used as a competitive platform for $n=20$ student-applicant contestants. The Cumulative Grade Point Average rankings of 20 randomly selected final year studentapplicants were used for the test. Results show that the CGPA performance ranking of the student-applicants differ from that of the HCI using the framework. A Wilcoxon Signed-Ranks Test was used to determine if the disparity in performance ranking was significant. Results show that there is indeed a significant difference in the performance ranking of the student-applicants using both approaches. The automated Construct was implemented using PHP and Mysql and deployed at (hcipredictor.eu3.org).
\end{abstract}

Keywords-Memory recall ability; processing speed; Sternberg paradigm; Posner paradigm; human capital intelligence; SemiLatin square

\section{INTRODUCTION}

Human capital intelligence (HCI) is an embodiment of knowledge, creativity, talents, habits, social and personality attributes, inherent in a person which could be measured in terms of economic value. HCI is a major factor to be considered especially for labour recruitment, leadership positions and managerial posts. Choosing the appropriate labour force for a business venture, leadership ability or managerial position has always been an uphill task especially in developing countries. This is so because the emphasis and major criteria for choosing the labour force is based on paper qualification and certification of the applicants. This leads to erroneous judgment in the quality of labour employed. This is evidently true because the quality of education in such countries is questionable. The education system is characterized by untested facilitators, examination malpractice, inconsistent education policies and poor funding and a lot more. A Nigerian education critic decries the condition of her educational system which gets bedeviled by the day as people are no longer judged by the latent ability in them but the certificates they have gathered by whatever means [1]. As a result of these, education system of developing countries continues to produce half-baked graduates with low HCI value.
The implications are for more reaching. A lot of small scale business ventures and organizations had packed up due to incompetent labour force. Experts are being sought from developed countries for staff retraining and subsequent salvaging of ventures. Output from companies continues to dwindle in quality and number due to incompetent labour force. Business firms, institutions and the society at large continue to lack in competent and skilled labour force. The existing recruitment process is not producing the desired competent labour that is needed to contend with the fast increasing economic challenges and production requirements because it solely depends on certificates obtained from sick education system. The existing recruitment attempts at ascertaining proficiency relies on human resource tools which includes aptitude tests (either written or computer based) and basically oral interviews. These methods come with their short falls. A person's score in an aptitude test is known to be a function of the examiner, the subject matter focus and the educational background. These short falls raise doubts on issues like possibility of test questions being revealed by the examiners before the test, possibility of favoritism during oral interviews and other related issues. These challenges continue to make it difficult to select competent labour force with sound human capital Intelligence value especially in developing countries. One way to improve the quality of labour force is to focus on means of measuring Intelligence as a human capital value. Intelligence has been identified as a major index in recruitment. Intelligence is not only related to the extent of knowledge gained or acquired by the individuals. It reveals the capability to yield from proper training, reason conceptually, think and solve problems [2]. Intelligence varies among individuals hence the need for Intelligence tests. Intelligence tests are known to specifically measure abilities of a person while cognitive tests measure a person's learning in a specific subject area. Intelligence tests are known to produce desired results and high predictive values and when it is combined with well-structured interview it could have the highest predictive value of all the methods of selection [3]. The aim of this paper therefore is to proffer a standard method of measuring human capital intelligence of applicants for recruitment into establishments and industries rather than depending on their over-rated certificates. The sole objective is to ensure that the measurement is done under an equitable and competitive platform. The measurement is achieved using a short memory test which has speed and memory recall abilities as its yardstick.

*Corresponding Authors. 
The major aim of the research therefore is to present a framework for measurement of processing speed and memory intelligence domains as HCI parameter which was lacking in [4]. The specific objective is to test the developed framework using 20 graduating student-applicants of the department of Computer science, University of Nigeria, Nsukka. The research question is interested in finding out if the results from the existing approach are the same as that of the proposed system under the hypothesis that:

\section{H0: The results from both approaches are the same}

Vs

\section{H1: The results from both approaches differ}

The significance of the work is to use the developed framework to especially aid human resource and recruiting agencies in recruiting more qualified labour that will enhance production.

\section{RESEARCH BASIS}

According to [5], Intelligence could be measured under three basic abilities: creative, analytical, and practical abilities. Defining Information processing in terms of creative Intelligence, then we will see it as the ability to convert latent information into manifest information [6]. If we also consider that in real time, information processing requires instant decisions within limited time, we will also see speed and perception as creative and analytical intelligence respectively. According to [4], five domains of Intelligence has been identified as Reasoning domain, Processing speed domain, Memory domain, Comprehension domain and an Unknown domain which may be in existence. These identified domains reduce to specific ability tests such as reasoning tests, speed tests, memory tests and spatial tests. The challenge has always been how to proficiently measure these abilities distinctly. For instance, attempts at measuring the memory recall ability has been and is still ongoing. According to the authors in [7], [8], [9] and [10], several attempts had been made at measuring memory using mathematical models such as SAM, REM, MINERVA 2 model, EEG analysis and ERP. Although foundational research on memory argues that short term memory differ from long term memory which presumes that their method of measurement should also differ. However, recent unified attempt at measuring memory ability is seen in [11] and [12] where EEG, FMRI studies and Serial Recall Paradigms. It is not therefore the difference in memory ability that matters but the mode of measurement. Most of the existing measuring procedures attempt to measure these distinct domains using a generalization approach which arguably does not address the peculiar nature of these domains. For instance, Human intelligence and memory recall ability has been measured in literature using the Sternberg paradigm [13]. Sternberg information processing is an information processing paradigm that tests an individual recalling ability. It thrives to ascertain intelligence ability of humans to scan the memory in high speed for information retrieval. The Sternberg experiment involves different trials of experiment in which a random series of say from one to six different digits are displayed at fixed point on the screen for 1.2 seconds delay time. Also given a test digit after a 2 seconds delay time, subjects are to judge whether the test digit is contained in a short memorized sequence of digits previously displayed. In this manner, high speed scanning ability in human memory could be determined per individual and could be used as a measure of intelligence. Similarly, human intelligence and memory recall ability has been measured using Posner approach. The task presents participants with pairs of uppercase, lowercase, and mixed-case letters (drawn from the set A, a, B, b) side by side, $0.5 \mathrm{~cm}$ apart on the screen, and these participants were asked to determine, as quickly as possible, whether the letters were the same or different according to a particular rule. Participants indicated that the letters were the same by pressing the $M$ key on a standard keyboard and different by pressing the Z key [14]. These two methods of measuring human intelligence have proved successful and had been the basis of research for many years. It has also been applied to animals in successfully measure of psychometric intelligence and reaction times in pigeons [15]. Unfortunately, these paradigms were applied solely for either Speed or memory recall ability. In other words, the measurement does not take into cognisance other domains of Intelligence. Secondly, the test is a onetime effort which may not really reflect the true ability of the participant in question. There is also no active interactive competition among the participants. Semi-Latin square presents a perfect platform for competition among participants whose human capital intelligence value is to be measured. Semi-Latin squares have found application in many areas of life. In Agricultural experiments for instance, the work of [16] gives credence to the use of a special group of Semi-Latin square known as Trojan squares as an experimental design.

\section{THEORETICAL BACKGROUND}

\section{A. Semi-Latin Square for Equitable and Competitive Platform}

According to [17], an $(\mathrm{n} \times \mathrm{n}) / \mathrm{k}$ Semi-Latin square is an $\mathrm{n} \times$ $\mathrm{n}$ array containing $n k$ letters in such a way that each rowcolumn intersection contains $k$ letters and each letter occurs once in each row and once in each column. It suffices to say that no letter occurs more than once in each row and in each column where they are found. There exists a special type of Semi-Latin square called Trojan Square. A Trojan square is simply an arrangement obtained by superposition of $k$ mutually orthogonal $\mathrm{n} \times \mathrm{n}$ Latin square (where such square exists), involving $k$ disjoint sets of $\mathrm{n}$ varieties so that the resulting square has $k n$ varieties, each occurring in $n$ experimental units, $n$ rows and $n$ columns, with each row intersecting each column in a block of $k$ experimental units. Trojan squares are constructed by superposition of two mutually orthogonal Latin squares. Trojan squares are known to be A-, D- and E-optimal among all binary incomplete-block designs of the same size [17]. The optimality feature of Trojan squares gives credence for using them in developing the competitive platform for assessing contestants.

\section{B. Construction of Semi-Latin Squares}

A Semi-Latin square is constructed by superposition of the Latin squares for instance, given two Latin squares 1 and 2, a semi-Latin square is obtained by superimposition of Latin squares as shown in Fig. 1. 




Latin Square 1

Semi-Latin Square

\begin{tabular}{|l|l|l|}
\hline $\mathrm{B}$ & $\mathrm{D}$ & $\mathrm{F}$ \\
\hline $\mathrm{F}$ & $\mathrm{B}$ & $\mathrm{D}$ \\
\hline $\mathrm{D}$ & $\mathrm{F}$ & $\mathrm{B}$ \\
\hline
\end{tabular}$\longrightarrow$\begin{tabular}{|l|l|l|}
\hline $\mathrm{AB}$ & $\mathrm{CD}$ & $\mathrm{EF}$ \\
\hline $\mathrm{CF}$ & $\mathrm{EB}$ & $\mathrm{AD}$ \\
\hline $\mathrm{ED}$ & $\mathrm{AF}$ & $\mathrm{CB}$ \\
\hline
\end{tabular}

Fig. 1. A $(3 \times 3) / 2$ Semi-Latin Square.

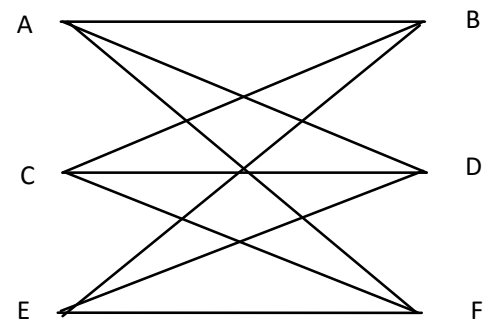

Fig. 2. $(3 \times 3) / 2$ Bipartite Variety Concurrence Graph.

The bipartite variety concurrence graph of the semi-Latin square is also shown in Fig. 2.

\section{Modified Sternberg and Posner Paradigm for Analytical and Creative Intelligence}

The Sternberg paradigm for analytical test of human intelligence tests for the ability and speed to recall and give answers to analytical problems. The HCI uses a modified version of the paradigm to test for analytical intelligence. The Sternberg paradigm in [12] was modified by displaying computer simulated arithmetic expressions requiring each contestant to complete under 5 seconds e.g. $5+[$ ] $=-2$. Similarly, a selection of pictures ranging from household items, fruits, human body parts and animals were randomly displayed in an inverted mode for contestants to quickly identify in less than 5 seconds. Similarly, the Posner paradigm was also modified to test for creative intelligence. The Posner paradigm was also modified by asking the contestants to identify missing vowels in certain words and displaying some reversed words for the contestants to identify the word within 5 seconds. The words used in this expert system are less than or equal to 5 in length and are obtained from advanced learners dictionary.

\section{Methodology}

An experiment was carried out using the CGPA (Cumulative Grade Point Average) of twenty (20) graduating students of the Department of Computer Science, University of Nigeria, Nsukka. The students were randomly selected from the 2017/2018 Departmental Board approved list of batch A graduating students. The 20 student-applicants are the contestants competing to be employed into establishments and companies based on their final CGPA and class of honors. Their final CGPA represents their actual performance in school. After obtaining their CGPA, the students were then subjected to a $(5 \times 5) / 4$ Trojan Semi-Latin square competitive platform where they were tested for creative and analytical intelligence using Sternberg and Posner paradigms.

\section{A. Construction of Semi-Latin Square for the Competitive Platform}

The twenty students were first divided into four groups of five (5) students each. Using only their user names and designated symbols, the layout is shown in Table I and Table II.

The four groups gave rise to four sets of mutually orthogonal Latin squares which were constructed using the following equation [18].

$$
a_{i j}^{h}(i \pm h j) \bmod 5
$$

The four Latin squares are then superimposed together to get the $(5 \times 5) / 4$ Trojan square in Table III.

TABLE. I. LAYOUT OF THE STUDENTS' GROUPS

\begin{tabular}{|l|l|l|l|}
\hline OFFOR (1) & GIFT (A) & NGO (a) & OKPA (@) \\
\hline UGWU (2) & KACH (B) & EZE (b) & CHI (\#) \\
\hline EMMA(3) & VIN (C) & OBI (c) & UCHE (\$) \\
\hline JOHN(4) & UWA (D) & ROSE (D) & KALU (\%) \\
\hline IKE(5) & AGHA (E) & OKO (e) & JOEL (\&) \\
\hline
\end{tabular}

TABLE. II. LAYOUT OF THE COMPETITIVE PLATFORM

\begin{tabular}{|c|c|c|c|c|c|c|c|c|c|}
\hline \multicolumn{5}{|c|}{ Latin 1} & \multicolumn{5}{|c|}{ Latin 2} \\
\hline 1 & 2 & 3 & 4 & 5 & A & B & $\mathrm{C}$ & $\mathrm{D}$ & $\mathrm{E}$ \\
\hline 2 & 3 & 4 & 5 & 1 & $\mathrm{D}$ & $\mathrm{E}$ & A & B & $\mathrm{C}$ \\
\hline 3 & 4 & 5 & 1 & 2 & B & $\mathrm{C}$ & $\mathrm{D}$ & E & A \\
\hline 4 & 5 & 1 & 2 & 3 & $\mathrm{E}$ & A & B & $\mathrm{C}$ & D \\
\hline 5 & 1 & 2 & 3 & 4 & $\mathrm{C}$ & $\mathrm{D}$ & $\mathrm{E}$ & A & B \\
\hline \multicolumn{5}{|c|}{ Latin 3} & \multicolumn{5}{|c|}{ Latin 3} \\
\hline $\mathrm{a}$ & $\mathrm{b}$ & $\mathrm{c}$ & $\mathrm{d}$ & $\mathrm{e}$ & @ & $\#$ & $\$$ & $\%$ & $\&$ \\
\hline $\mathrm{c}$ & $\mathrm{d}$ & $\mathrm{e}$ & $\mathrm{a}$ & $\mathrm{b}$ & $\&$ & @ & $\#$ & $\$$ & $\%$ \\
\hline $\mathrm{e}$ & $\mathrm{a}$ & $\mathrm{b}$ & $\mathrm{c}$ & $\mathrm{d}$ & $\%$ & $\&$ & $@$ & $\#$ & $\$$ \\
\hline $\mathrm{b}$ & $\mathrm{c}$ & $\mathrm{d}$ & $\mathrm{e}$ & $\mathrm{a}$ & $\$$ & $\%$ & $\&$ & @ & $\#$ \\
\hline $\mathrm{d}$ & $\mathrm{e}$ & $\mathrm{a}$ & $\mathrm{b}$ & $\mathrm{c}$ & $\#$ & $\$$ & $\%$ & $\&$ & @ \\
\hline
\end{tabular}

TABLE. III. SEMI-LATIN SQUARE FOR TESTING TwENTY APPLICANTS

\begin{tabular}{|l|l|l|l|l|l|}
\hline Sess & Grp1 & Grp2 & Grp3 & Grp4 & Grp5 \\
\hline 1 & 1,A,a,@ & 2,B,b,\# & 3,C,c,\$ & 4,D,d,\% & 5,E,e,\& \\
\hline 2 & 2,D, c, \& & 3,E, d, @ & 4,A, e,\# & 5,B, a,\$ & 1,C, b,\% \\
\hline 3 & 3,B, e,\% & 4,C, a,\& & 5,D, b, @ & 1,E, c,\# & 2,A, d,\$ \\
\hline 4 & 4,E, b,\$ & 5,A, c,\% & 1,B, d,\& & 2,C, e,@ & 3,D, a,\# \\
\hline 5 & 5,C, d,\# & 1,D, e, \$ & 2,E,a,\% & 3,A, b,\& & 4,B, c,@ \\
\hline
\end{tabular}




\section{B. Experimental Procedure}

The constructed $(5 \times 5) / 4$ Trojan square ensures that each contesting candidate competes with others especially from opposite class for $n=5$ times. The experiment was carried out in 5 sessions each having 5 groups of 4 students. The students competed among themselves at the same time in different groups and session. This means that for a given session, the Sternberg and Posner tests run concurrently for each group in that session. The Trojan square also ensures that no contestant will be in more than one group in a session because completion for every group in a given session goes on simultaneously with others. The creative and analytical intelligence tests contestants on the four major domains of intelligence which are Reasoning domain, Processing speed domain, Memory domain, Comprehension domain as identified in [4].

As each group competes, the position ranking of each student is taken. The final score obtained is dependent on both the position ranking and the total score for all the groups. The questions were classified into: Posner reversed word test, Posner missing word vowel test, Sternberg Arithmetic test, Sternberg inverted alphabet test and Sternberg inverted picture test.

\section{Score Sheet}

The Experiment was carried out under the following control constraints:

a) Questions are automatically generated by the system in real time ensuring that students or administrators do not have prior knowledge of the questions before hand.

b) Equal time duration for each question displayed.

c) Each group in a session answers the same questions.

d) Each student answered a total of hundred (100) questions coming from Posner and Sternberg modified short memory tests.

e) Each contestant logs into the application and completes the test.

In general, for any Semi-Latin square $(n \times n) / k$ platform, the total number of questions per contestant is given as:

$\mathrm{TQ}=20 *((\mathrm{n} * \mathrm{k}) / \mathrm{k})$

If $\mathrm{n}=3$ and $\mathrm{k}=2$ (i.e $(3 \times 3 / 2)=6$ ) then total no of Questions per candidate $=20 * 3=60$, If $\mathrm{n}=5$ and $\mathrm{k}=4$ (i.e $(5 \times 5 / 4)=10)$ then total no of questions $=20 * 5=100$

\section{Score Inference Engine}

If letter $\boldsymbol{A}$ represents the students answer for a question and letter $\boldsymbol{B}$ represents the correct answer to a question, then using the set of logical values as Boolean algebra, the score inference engine is represented thus:

$($ Posner Reversed word test $)=$

$\{T, \quad$ If $A=B$

F, Otherwise
(Posner Missing Vowel test $)=$

$$
\left\{\begin{array}{c}
T, \quad \text { If len }(A)=\text { len }(B) \text { AND } B \in D \text { (Dictionary ) } \\
F, \text { Otherwise }
\end{array}\right.
$$

$($ Sternberg Arithmetic test $)=$

$$
\begin{cases}T, & \text { If } A=B \\ F, & \text { Otherwise }\end{cases}
$$

$($ Sternberg Inverted Alphabet test $)=$

$\begin{cases}T, & \text { If } A=B \\ F, & \text { Otherwise }\end{cases}$

$($ Sternberg Inverted Pictures test $)=$

$\left\{\begin{array}{l}T, \quad \text { If } A=B \\ F, \quad \text { Otherwise }\end{array}\right.$

The score inference engine layout is summarized in Table IV.

\section{E. Applicatn Screen Shots}

Some of the screen shots from the application showing examples of test questions are shown in Fig. 3 and Fig. 4.

TABLE. IV. SCORE INFERENCE ENGINE

\begin{tabular}{|l|l|l|l|l|}
\hline Test & $\begin{array}{l}\text { Contestant } \\
\text { answer (A) }\end{array}$ & $\begin{array}{l}\text { Correct } \\
\text { answer (B) }\end{array}$ & Rule & Score \\
\hline $\begin{array}{l}\text { Posner reversed } \\
\text { word test }\end{array}$ & A & B & If A=B then & True \\
\hline $\begin{array}{l}\text { Posner missing } \\
\text { vowels test }\end{array}$ & A & B & $\begin{array}{l}\text { If len(A) }= \\
\text { len(B) and A } \\
\text { found in } \\
\text { dictionary) } \\
\text { then }\end{array}$ & True \\
\hline $\begin{array}{l}\text { Sternberg } \\
\text { Arithmetic test }\end{array}$ & A & B & If A=B then & True \\
\hline $\begin{array}{l}\text { Sternberg } \\
\text { inverted alphabet } \\
\text { test }\end{array}$ & A & B & B & If A=B then \\
\hline $\begin{array}{l}\text { Sternberg } \\
\text { inverted pictures } \\
\text { test }\end{array}$ & A & True \\
\hline
\end{tabular}

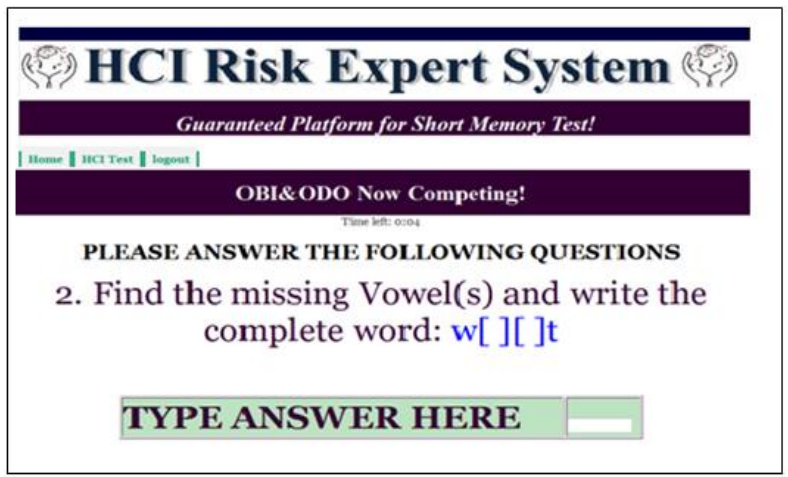

Fig. 3. Posner Missing Vowel Test for Creative Intelligence. 


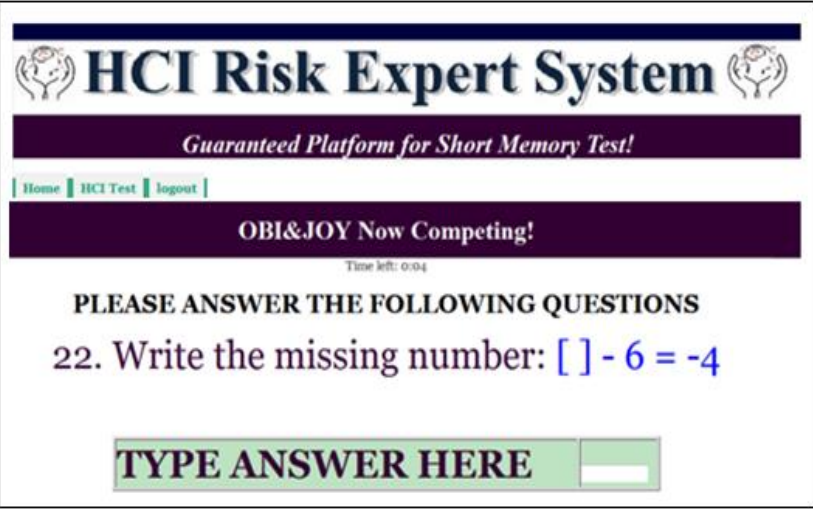

Fig. 4. Sternberg Arithmetic Test for Analytical Intelligence.

\section{ANALYSIS AND RESULTS}

\section{A. Analysis}

Using the competitive Semi-Latin square platform show in Table III, the Posner and Sternberg test for memory and speed processing was carried out by the developed application. Each scheduled group of four (4) competing applicants is meant to answer twenty (20) questions. The performance ranking of each applicant is noted for each competition. In this case, there were five (5) competition schedules which gave five (5) different performance ranking and another five (5) different sub total score for each applicant. The scaled CGPA score represents the contestant's score based on the Senate approved CGPA. The scaled CGPA is computed using the following equation:

CGPA score $=\frac{C G P A}{5.0} \times \frac{100}{1}$

The HCI score is obtained by taking into cognizance the total score for each student in all the sessions and their respective total rank score (TR). The result is then scaled to 100 percent. The HCI score is obtained using:

HCI score $=\left(\frac{C G P A \_s c o r e}{T Q} \times \frac{n}{T R} \times \frac{100}{1}\right)$

Where $\mathrm{TQ}=$ total questions, $T R$ represents the total performance ranking of each student based on their position after every successful group competition.

For instance, IKE has a CGPA score $=56.6, \mathrm{TR}=14, \mathrm{TQ}=$ $100, \mathrm{n}=5$. The HCI score will thus be calculated as:

HCI score $=\left(\frac{56.6}{100} \times \frac{5}{14} \times \frac{100}{1}\right)=20.21$

The CGPA ranking is obtained by taking the position of each contesting student based on the CGPA. Similarly, the IQ ranking is obtained by taking the position of each contesting student based on their IQ score.

\section{B. Results Obtained}

The system successfully measured the HCI value of the twenty (20) students. The results are compared to their CGPA's as shown in Table V.

A bar chart showing the deviation between the CGPA and HCI ranking is shown in Fig. 5.
The results obtained showed that there was a disparity between the performance rankings of the two approaches. In order to ascertain whether the deviation was really significant, the Wilcoxon Signed-Ranks Test was carried out using the students CGPA score and the obtained HCI score. Firstly, a normality test on the difference between the two scores from both methods was carried out. The results are shown in Table VI and Fig. 6, respectively.

TABLE. V. CGPA AND HCI SCORES

\begin{tabular}{|c|c|c|c|c|c|c|c|c|}
\hline 目 & 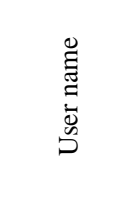 &  & $\begin{array}{l}0 \\
0 \\
0 \\
\infty \\
0 \\
0\end{array}$ & 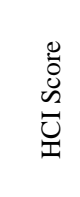 & 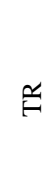 & 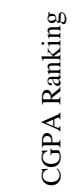 & 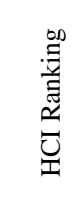 & مَ \\
\hline 1 & IKE & 2.83 & 56.6 & 20.21 & 14 & 13 & 11 & 2 \\
\hline 2 & OFOR & 4.65 & 93.0 & 93.00 & 5 & 1 & 2 & 1 \\
\hline 3 & UGWU & 2.52 & 50.4 & 15.75 & 16 & 16 & 13 & 3 \\
\hline 4 & EMMA & 4.59 & 91.8 & 91.80 & 5 & 2 & 1 & 1 \\
\hline 5 & JOHN & 3.30 & 66.0 & 23.57 & 14 & 12 & 17 & 5 \\
\hline 6 & AGHA & 2.77 & 55.4 & 15.11 & 18 & 14 & 16 & 2 \\
\hline 7 & VIN & 1.69 & 33.8 & 9.70 & 20 & 20 & 18 & 2 \\
\hline 8 & GIFT & 2.29 & 45.8 & 12.05 & 19 & 17 & 10 & 3 \\
\hline 9 & UWAH & 3.91 & 78.2 & 32.58 & 12 & 9 & 9 & 0 \\
\hline 10 & $\mathrm{KACH}$ & 2.08 & 41.6 & 10.40 & 20 & 19 & 19 & 0 \\
\hline 11 & OKO & 4.03 & 80.6 & 57.57 & 7 & 4 & 5 & 1 \\
\hline 12 & EZE & 2.18 & 43.6 & 12.11 & 18 & 18 & 15 & 3 \\
\hline 13 & ROSE & 4.01 & 80.2 & 57.29 & 7 & 5 & 4 & 1 \\
\hline 14 & NGO & 4.31 & 86.2 & 61.57 & 7 & 3 & 3 & 0 \\
\hline 15 & OBI & 3.45 & 69.0 & 28.75 & 12 & 11 & 14 & 2 \\
\hline 16 & JOEL & 2.74 & 54.8 & 19.57 & 14 & 15 & 20 & 5 \\
\hline 17 & KALU & 3.49 & 69.8 & 31.73 & 11 & 10 & 12 & 2 \\
\hline 18 & UCHE & 3.93 & 78.6 & 39.30 & 10 & 7 & 7 & 0 \\
\hline 19 & $\mathrm{CHI}$ & 4.01 & 80.2 & 40.10 & 10 & 6 & 6 & 0 \\
\hline 20 & OKPA & 3.68 & 73.6 & 33.45 & 11 & 8 & 8 & 0 \\
\hline
\end{tabular}

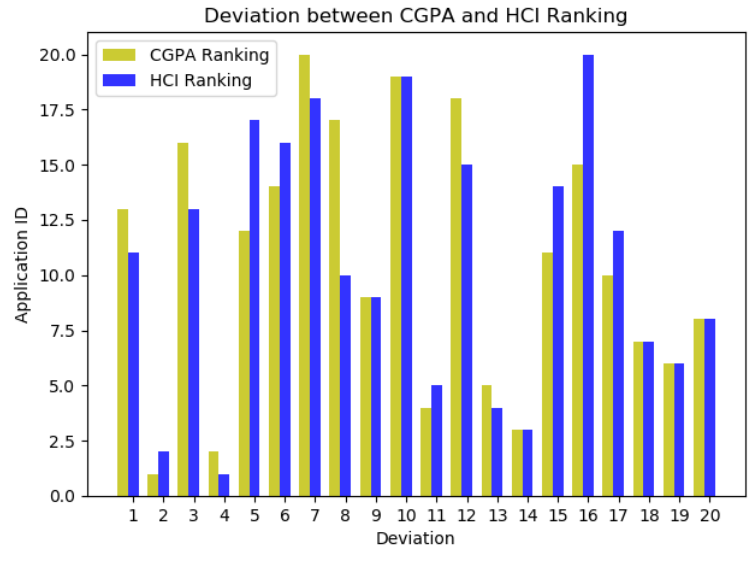

Fig. 5. Deviation between CGPA and HCI Ranking. 
TABLE. VI. TESTS OF NORMALITY

\begin{tabular}{|l|l|l|l|l|l|l|}
\hline & \multicolumn{3}{|l|}{ Kolmogorov-Smirnov ${ }^{\mathrm{a}}$} & \multicolumn{3}{|c|}{ Shapiro-Wilk } \\
\hline & Statistic & df & Sig. & Statistic & df & Sig. \\
\hline Diff_HCI_CGPA & .201 & 20 & .034 & .813 & 20 & .001 \\
\hline
\end{tabular}

a.Lilliefors Significance

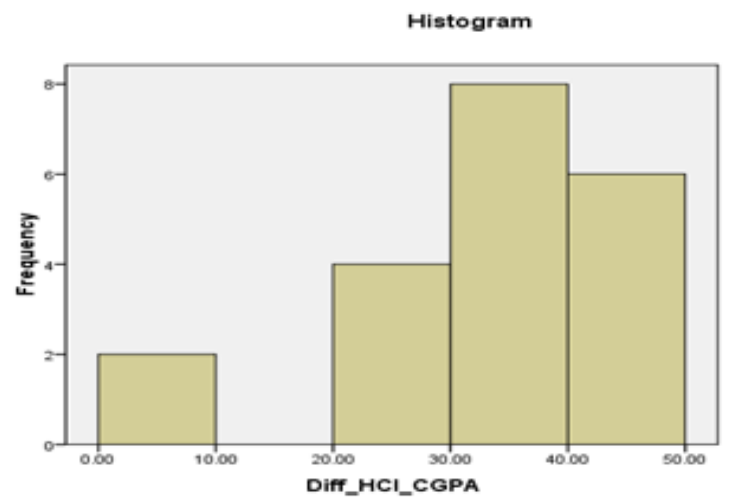

Fig. 6. Normality Test on Data Set.

The reported $P$ value $(0.034$ and 0.001$)$ are all less than 0.05 , and the histogram was right skewed, hence we conclude that the data was not normally distributed. As a result of the failed normality test, an alternative non-parametric test was used. The Wilcoxon Signed-Ranks Test was used to determine whether there was actual difference in the results obtained from both methods.

The null hypothesis which says that the two methods are the same was tested against the alternative which says that the two methods vary.

$$
\begin{aligned}
& \mathrm{H}_{0} \text { : CGPA_Score }=\text { HCI_Score } \\
& \mathrm{Vs} \\
& \mathrm{H}_{1} \text { : CGPA_Score } \neq \text { HCI_Score }
\end{aligned}
$$

The result of the Wilcoxon Signed-Ranks test is shown in Table VII.

The Wilcoxon Signed-Ranks Test Result shows that the Asymp. Sig. (2-tailed) value was 0.00 and less than 0.05. As a result, the null hypothesis was rejected while the alternative was accepted. The conclusion therefore is that the two methods produce different results contrary to expectation.

TABLE. VII. WILCOXON SIGNED-RANKS TEST RESULT

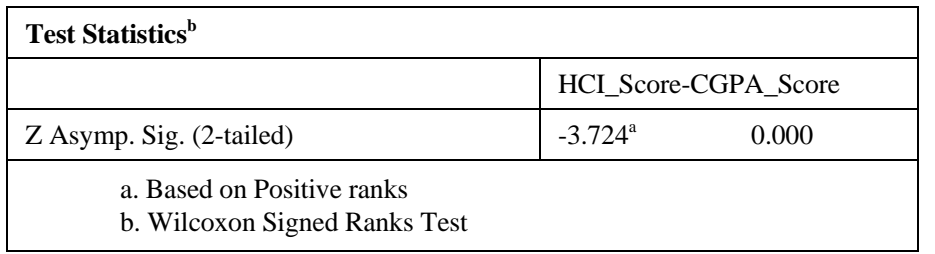

\section{CONCLUSION}

The framework was successful in measuring the processing speed and memory intelligence domains. The results obtained show that the existing approach to recruitment which emphasizes academic performance differs from the proposed framework which on the other hand lays more emphasis on processing speed and memory recall ability. Results show that the position ranking of the student-applicants based on their final CGPA results differ from their HCI ranking. The Wilcoxon Signed-Ranks Test which was significant at 0.00 validates the disparity. One would expect that their CGPA performance should tally with their HCI result under the developed construct but it wasn't so. The best candidate in the CGPA ranking is not necessarily the best in the HCI ranking. The Semi-Latin square construct could be said to be a true representation of the students' intelligence virtue because:

a) The 20 students had equal opportunity and constraint to compete with one another.

b) There was more than one session of test thereby reducing the issue of unfamiliarity of the system.

c) The questions from the construct were simulated and are not known beforehand.

d) The questions are not limited to a discipline but only test for creative and analytical intelligence using what the students could reason out within a short time.

\section{PROSPECTS FOR FUTURE RESEARCH}

Future research interest should therefore focus on using creative and analytical intelligence as a major criteria for recruitment rather than placing so much emphasis on applicant's certificates. Interest should also focus on increasing the number of applicants from 20 to a higher number in order to fit into practical situations.

\section{REFERENCES}

[1] S. Obanubi, "The Love of Certificate:Where to Nigeria?". January 15, 2015. Retrieved from :http://unitenigeria.com/nigeria-and-the-love-ofcertificate/.

[2] H.G. Uzma and H. Tajammal. "Comparative Study of Intelligence Quotient and Emotional Intelligence: Effect on Employees' Performance". Asian Journal of Business Management January 15, 2013, Vol 5(1): Pg 153-162, Retreived from: https://doi.org/10.19026/ajbm.5.5824.

[3] F.L. Schmidt and J.E. Hunter "The validity and utility of selection methods in personnelpsychology: practical and theoretical implications of 85 years of research findings. Psychological Bulletin, 1998, 124 (2), pp 262-74,Retreived from: https://doi.org/10.1037/00332909.124.2.262.

[4] L.. Matzel and B. Sauce "IQ. In: Vonk J.Shackelford T. (eds) Encyclopedia of Animal Cognition and Behavior". Springer, Cham, 2017, https://doi.org/10.1007/978-3-319-47829-6_1080-1axwell, A Treatise on Electricity and Magnetism, 3rd ed., vol. 2. Oxford: Clarendon, 1892, pp.68-73.

[5] D. McGonigle and K. Mastrian " Introduction to information, information science, and information systems. Jones \& Bartlett, 2011. Retrieved from: http://samples.jbpub.com/9781449631741/92367_ CH02_017_032.pdf 
[6] G.W Jeroen and M.S. Richard, "Models of Memory"in Stevens", Handbook of Experimental Psychology, Third Edition, 1988, Volume 2: Memory and Cognitive Processes. (Pp.43-76). New York: JohnWiley\&Sons,Inc.

[7] H.U. Amin, A.S Malik., N. Badruddin and,W.T Chooi “ Brain Behavior in Learning and Memory Recall Process: A High-Resolution EEG Analysis. In: Goh J. (eds) The 15th International Conference on Biomedical Engineering. IFMBE Proceedings, vol 43. Springer, 2014.

[8] H.U Amin, A.S. Malik, S. Aamir, N. Kamel, W.T Chooi and H.Muhammad. "P300 correlates with learning \& memory abilities and fluid intelligence", Journal of NeuroEngineering and Rehabilitation, Vol 12, Article number: 87, $23^{\text {rd }}$ September, 2015.

[9] S. Hanouneh, H.U. Amin, N.M. Saad and A.S Malik. "The correlation between EEG asymmetry and memory performance during semantic memory recall," 2016 6th International Conference on Intelligent and Advanced Systems (ICIAS), Kuala Lumpur, 2016, pp. 1-4. doi: 10.1109/ICIAS.2016.7824041.

[10] Mc Hafeezullah Amin, and A.S. Malik "Human memory retention and recall processes A review of EEG and fMRI studies", Neurosciences 2013; Vol. 18 (4)

[11] M.S. Ahmed and S.A. Yasir "Examining the Effect of Interference on Short-term Memory Recall of Arabic Abstract and Concrete Words Using Free, Cued, and Serial Recall Paradigms", Advances in Language and Literary Studies, December 2015, Vol. 6 No. 6, ISSN: 2203-4714.
[12] S. Sternberg. "High-Speed Scanning in Human Memory", Science, New Series, Vol.153, No. 3736. Pp. 652-654, August, 1966. Made Available by JSTOR on September, 2005 Retrieved from:http://www.jstor.org/.

[13] A. Douglas and F. Bert "Age, Speed of Information Processing, Recall, and Fluid Intelligence". University of Toronto, Scarborough Campus, Ontario, Canada., pg. 229-248, 1995.echnical Writer's Handbook. Mill Valley, CA: University Science, 1989.

[14] C. N. Aljoscha, R. Rainer, M. Ralf and A. Alois "Intelligece and Reaction Times in the Hick, Sternberg and Posner Paradigms". Person. individ. Diff. 1997, Vol. 22, No. 6, pp. 885-894ouglas and F. Bert "Age, Speed of Information Processing, Recall, and Fluid Intelligence". University of Toronto, Scarborough Campus, Ontario, Canada., pg. 229248, 1995.echnical Writer's Handbook. Mill Valley, CA: University Science, 1989.

[15] D.A. Preece and G.H. Freeman, "Semi-Latin squares and related designs. J.Roy.Statist.Soc. Ser. B45, 267-277, 1983, retrieved from: https://doi.org/10.1111/j.2517-6161.1983.tb01250.x.

[16] R.A. Bailey and P.E. Chigbu, Enumeration of Semi-Latin Squares, Discrete math, 1997, 167/168, Pg 73-84, Retrieved from: https://doi.org/10.1016/S0012-365X(96)00217-8.

[17] R.A. Bailey. "Efficient Semi-Latin squares". Statistica Sinica 1992, Vol.2 (413-437).

[18] R.N. Mohan, M. Ho Lee, and S.S. Pokhrel, On Orthogonality of Latin Squares, J. Comb. Infor. System Sci., 2005, Vol.30(1-4), Pg151- 179. Retrieved from: https://www.researchgate.net/publication/1959255_ On_Orthogonality_of_Latin_Squares 